\title{
О происхождении главного пояса астероидов
}

\author{
Н.Н. Горькавый \\ ФГБУН “Крымская астрофизическая обсерватория РАН”, Научный, Крым, 298409 \\ gorkavyi@yandex.ru
}

Поступила в редакцию 26 февраля 2018 г.

\begin{abstract}
Аннотация. Обсуждается происхождение главного пояса астероидов, тесно связанное с проблемой уменьшения суммарной массы астероидов на три порядка по сравнению с первоначальной массой протопланетного диска в данной зоне. Рассматривается ранее неизученный механизм уменьшения массы астероидного пояса, связанный с выметанием мелких пылинок из пояса астероидов. Основными динамическими факторами являются давление солнечного излучения и ветра, эффект Пойнтинга - Робертсона и гравитационное рассеяние пылинок на планетах-гигантах, в первую очередь на Юпитере. Показано, что данный механизм столкновительной эрозии мог сыграть значимую роль в формировании главного пояса астероидов.

ON THE ORIGIN OF THE MAIN ASTEROID BELT, by N.N. Gorkavyi. The paper discusses the origin of the main asteroid belt closely related to the problem of decreasing the total mass of asteroids by three orders of magnitude in comparison with the initial mass of the protoplanetary disk in this zone. We consider a previously unexplored mechanism for reducing the mass of the asteroid belt connected with sweeping out small dust particles from the asteroid belt. The main dynamic factors are solar radiation and solar wind pressure, the Poynting-Robertson effect and gravitational scattering of dust particles on giant planets, primarily on Jupiter. It is shown that this mechanism of collisional erosion could play a significant role in the formation of the main asteroid belt.
\end{abstract}

Ключевые слова: астероиды, Солнечная система

\section{1 Введение}

Проблема образования главного пояса астероидов возникла вскоре после обнаружения первого астероида Цереры 1 в 1801 году. Ольберс, открывший в 1802 году малую планету Палладу 2, в 1804 году выдвинул идею, что астероиды возникли из-за развала большой планеты. Эта гипотетическая планета стала известна как планета Ольберса или планета Фаэтон. Идея развала или взрыва планеты, располагавшейся между Марсом и Юпитером, оказалась удивительно живучей не только среди фантастов и широкой публики. Ее обсуждение в астрономической среде продолжалось еще в 70-х годах XX века (см. обзор в книге Витязева и др., 1990). Но большинство специалистов второй половины XX века пришло к выводу, что астероиды - это несформировавшаяся планета, на что указывали широкое распределение астероидов по большим полуосям орбит, а также зависимость альбедо и химсостава астероидов от расстояния до Солнца. Кроме того, не существует способа развалить достаточно крупную одиночную планету, двигающуюся по квазикруговой орбите и не сближающуюся 
с планетами-гигантами. Даже при таком катастрофическом сближении и при разрушительном воздействии приливных сил планета должна развалится на несколько кусков, а не на миллионы мелких тел.

Твердое мнение о том, что пояс астероидов возник на месте планеты, которой помешали образоваться, было высказано О.Ю. Шмидтом (см. изложение его взглядов и обзор его работ в брошюре Шмидт, 1962). Он писал про пояс астероидов: "Процесс планетообразования в этом поясе остановился на промежуточной стадии более мелких тел. Это обусловлено близостью массивного Юпитера и отмеченными выше особенностями температуры и состава тел, образующихся в этой зоне”. Шмидт имел в виду то, что в поясе астероидов из-за достаточно высокой температуры льды испарялись, а выживали только тугоплавкие вещества, аналогичные земным. Таким образом, на месте пояса астероидов должна была образоваться не массивная планета-гигант, а небольшая планета земной группы.

Шмидт отмечал, что влияние Юпитера вызвало рост эксцентриситетов и наклонений астероидных орбит, что вызвало увеличение относительных скоростей астероидов и доминирование разрушения над объединением. Действительно, современные скорости хаотического движения астероидов заметно больше, чем скорости убегания частиц с их поверхности, поэтому при столкновении астероиды разрушаются, а не слипаются, как полагается при образовании планет.

Рост хаотических скоростей астероидов и убыль их числа в щелях Кирквуда очевидно связаны с влиянием резонансов Юпитера, особенно если учесть эффект сканирования этих резонансов - то есть их движения по поясу астероидов из-за смещения Юпитера (см. Минтон и Мальхотра, 2009, 2010). Сценарий со значительным перемещением планет-гигантов по Солнечной системе имеет ряд проблем (Диенно и др, 2016). Отметим, что какая-то часть избытка хаотических скоростей над первыми космическими скоростями современных малых тел может быть связана с тем, что раньше астероиды были крупнее и их равновесная хаотическая скорость лучше соответствовала их первым космическим скоростям.

Увеличение средних хаотических скоростей астероидов из-за резонансов - процесс медленный, занимающий миллиарды лет, а характерное время образования планеты земной группы - сто миллионов лет. Почему же планета не успела образоваться до разогрева астероидного пояса? Главный фактор остановки роста потенциальной планеты, вероятно, заключается в том, что масса пояса астероидов на три порядка меньше, чем она должна была быть при экстраполяции плотности протопланетного диска из области Земли и Марса в область пояса астероидов. Возможно, быстрое уменьшение массы протопланетного диска между Марсом и Юпитером стало главной причиной резкого замедления роста потенциальной крупной планеты. Популярным является мнение, что юпитерианские резонансы выкачивают массу из пояса астероидов, образуя знаменитые щели Кирквуда. Но основная часть пояса астероидов является нерезонансной и малочувствительной к воздействию Юпитера, и неясно, насколько сканирование резонансов может решить эту проблему. Кроме того, если бы резонансный механизм доминировал бы в убыли массы, то существовал бы сильный градиент плотности астероидного пояса с уменьшением ее в направлении к Юпитеру и к области с наибольшим количеством его резонансов, в то время как такого градиента не наблюдается. В книге Витязева и др. (1990) в качестве механизма деградации протоастероидного диска рассматривается залет крупных тел из зоны Юпитера, которые вычерпывали вещество из зоны пояса астероидов. Но этот механизм малоисследован, в частности, легко предположить существование и обратного эффекта: крупные тела юпитерианской зоны, столкнувшись с астероидами, покинут семейство Юпитера и постепенно втянутся в главный пояс астероидов, увеличив его массу.

Целью данной статьи является обсуждение нового механизма уменьшения массы астероидного пояса, который должен быть рассмотрен наравне с другими причинами убыли массы астероидов. Этот механизм включает в себя три этапа:

1. Выброс мелких пылинок (микронного и субмикронного размеров) с поверхности астероидов из-за микрометеоритного обстрела или при соударениях крупных тел.

2. Перевод мелких пылинок на эллиптические орбиты из-за светового давления и солнечного ветра, из-за чего они могут сближаться с Юпитером в районе апогея своей орбиты.

3. Гравитационное рассеяние на Юпитере и выбрасывание пылинок в межзвездное пространство. 
Предположение о том, что этот механизм может внести свой вклад в уменьшение массы протоастероидной зоны и тем самым послужить одной из причин образования главного пояса астероидов, высказывалось автором ранее (Горькавый и Тайдакова, 2006; Горькавый и Тайдакова, 2016). Дополнительным доводом в пользу эффективности данного механизма является мультиимпактная модель образования спутников астероидов, которые вырастают при накоплении на орбите вещества, выброшенного с поверхности астероида ударами мелких метеороидов (Горькавый, 2007; Гафтонюк и Горькавый, 2013). Эта мультиимпактная модель объясняет регулярность астероидных спутников, то есть малые эксцентриситеты и наклонения их орбит. Аналогичная модель применима и к образованию Луны (Горькавый, 2007). Таким образом, наличие большого количества спутников возле астероидов указывает на постоянный поток вещества с астероида в межпланетное пространство.

\section{2 Орбитальная эволюция пылинок в Солнечной системе}

Рассмотрим сначала орбитальную эволюцию частиц. Движение пылинок, выброшенных с поверхности астероидов и других малых тел, с учетом светового давления, эффекта Пойнтинга-Робертсона и гравитационного воздействия крупных планет, рассчитывалось в ряде статей автора с соавторами (напр., Горькавый и др., 2000а, 2000б). Эти расчеты выявляют значительное воздействие светового давления на начальную форму орбиты пылинки и высокую частоту взаимодействия пылинок с гравитационным полем планет-гигантов. Последнее обеспечено не только огромной массой планетгигантов, но и эффектом Пойнтинга - Робертсона, который заставляет частицу дрейфовать к Солнцу и неизбежно пересекать зону сильных гравитационных возмущений от планет. Проиллюстрируем эти эффекты с помощью рисунков, взятых из статьи автора, опубликованной только на электронном ресурсе (Горькавый и др., 2000б). На рис. 1 показана эволюция орбиты пылевой частицы с размером 5-10 микрон (параметр Пойнтинга - Робертсона или отношение давления солнечного света к солнечной гравитации равен 0.057), унесенной с поверхности транснептуна, расположенного на расстоянии более 40 a.е. Путешествие этой частицы длится несколько миллионов лет и заканчивается тем, что частица сближается с Юпитером и выбрасывается его гравитационным полем на гиперболическую орбиту, после чего пылинка покидает Солнечную систему.

На рис. 2 показано распределение плотности мелкой пыли в 1-2 микрона (параметр Пойнтинга Робертсона равен 0.285) из пояса транснептунов в координатах большой полуоси и эксцентриситета. Рассчитана эволюция 200 частиц, первая половина из которых стартовала из перицентра орбит 100 транснептунов, а вторая половина - из апоцентров этих орбит. Расчет велся до падения частицы на Солнце или планету, или до выброса ее в межзвездное пространство. В распределении пыли отчетливо видны резонансные структуры. Видно, что каждая планета-гигант порождает поток пыли, уносимый в межзвездное пространство. Первоначальными источниками этой пыли могут быть транснептуны, кометы или астероиды.

На рис. 3 показана поверхностная плотность (в условных единицах) пыли размером в 1-2 микрона и 5-10 микрон из пояса транснептунов, усредненная по интервалу в 0.3 а.е. Были вычислены траектории 200 пылинок; каждая траектория была представлена набором рассчитанных точек, плотность которых вдоль гелиоцентрического расстояния и была определена для данного рисунка. Частицы размером в 5-10 микрон движутся под действием эффекта Пойнтинга-Робертсона медленнее мелких частиц, поэтому они образуют более плотный слой. Резкое падение плотности пылевого слоя в зоне Сатурна и Юпитера связано с гравитационным выбрасыванием частиц из Солнечной системы.

Результаты, отраженные на рис. 3, показывают, что более $90 \%$ микронных частиц, дрейфующих из зоны транснептунов, выбрасываются гравитационным полем планет-гигантов, в первую очередь Юпитером, из Солнечной системы. Аналогичный результат получен в расчетах Дхарсандии и др. (2017). Без учета планет характерное время дрейфа пылинок из пояса транснептунов к Солнцу составляет около 4 миллионов лет для мелких частиц в 1-2 микрона и около 10 миллионов лет для более крупных частиц в 5-10 микрон. Учет гравитационного воздействия планет, которое выражается в захвате пылинок во внешние резонансы и их рассеянии при сближении с планетами, увеличивает время эволюции частиц до 6-7 и 20 миллионов лет для мелких и крупных частиц соответственно. 


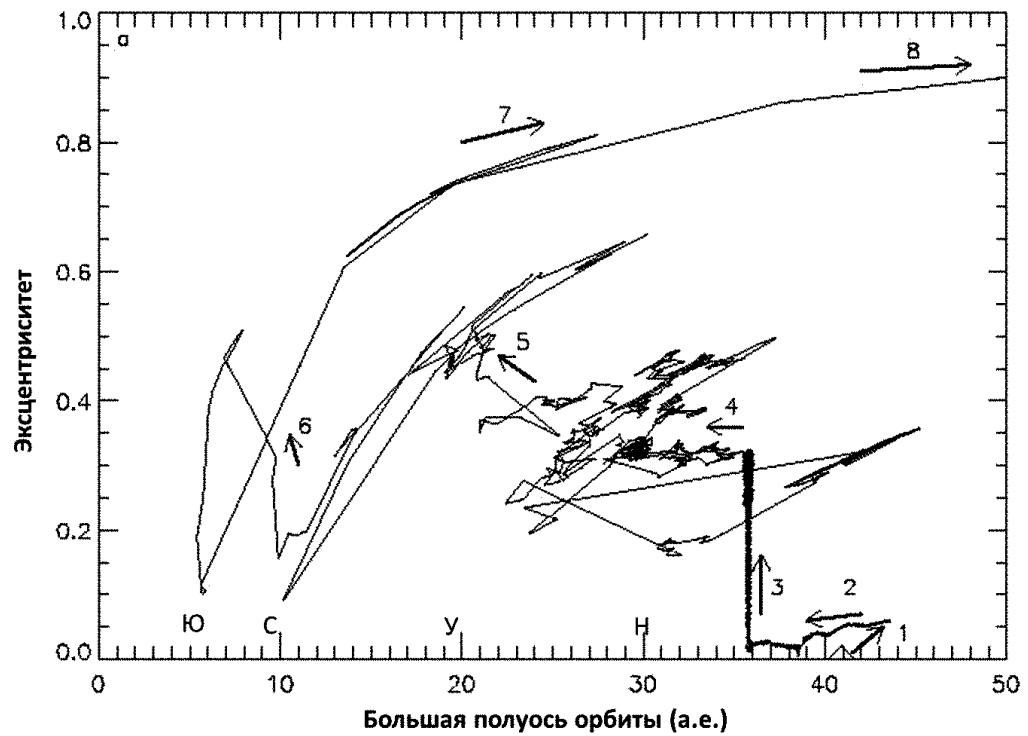

Рис. 1. Эволюция большой полуоси и эксцентриситета орбиты пылевой частицы с размером 5-10 микрон, унесенной с поверхности транснептуна. Показаны положения частицы каждые 5 тысяч лет (эти положения соединяются прямыми линиями). Основные этапы эволюции: 1 - пылинка соскакивает с родительского транснептуна и увеличивает свою полуось и эксцентриситет из-за светового давления; 2 - частица дрейфует к Солнцу под действием эффекта Пойнтинга-Робертсона; 3 - она захватывается во внешний резонанс 3:2 от Нептуна и долгое время сохраняет значение своей большой полуоси, увеличивая при этом эксцентриситет; 4 - частица сближается с Нептуном и вследствие гравитационного возмущения выходит из резонанса и начинает квазихаотическое движение в зонах действия Нептуна и Урана (расположение зон четырех планет-гигантов показано на рис. 2); 5 - частица сближается с Сатурном и переходит в его зону; 6 - частица перепрыгивает в зону Юпитера; 7-8 - частица двигается в зоне Юпитера, а потом выбрасывается его гравитационным полем в межзвездное пространство по орбите

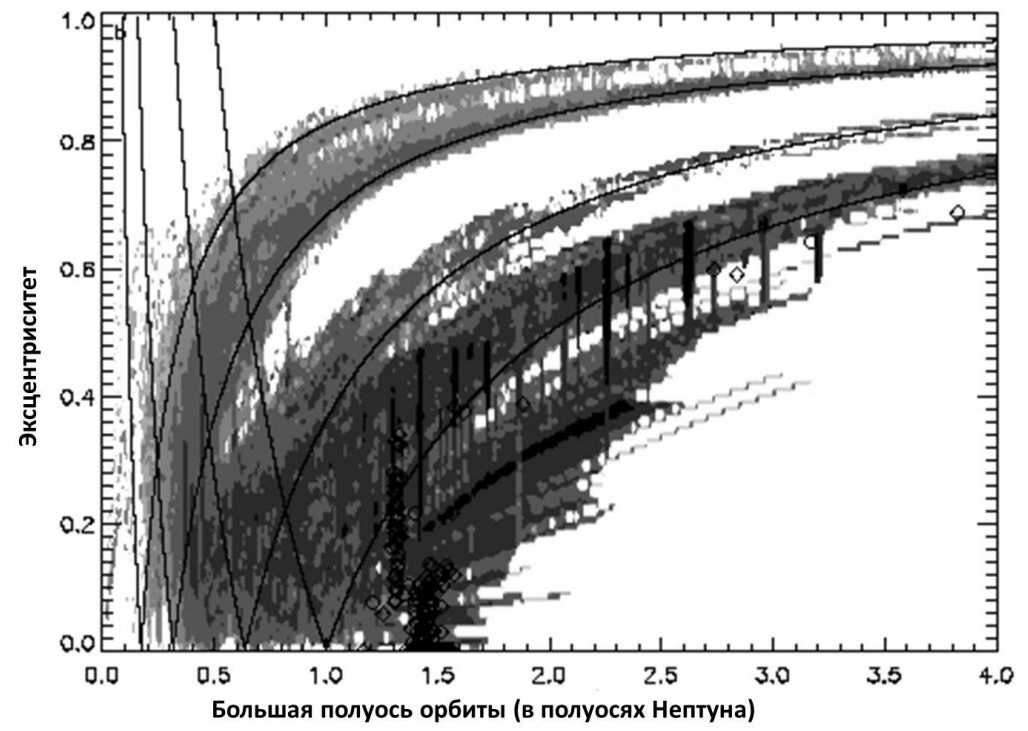

Рис. 2. Распределение плотности мелкой пыли (1-2 микрона) в пространстве орбитальных координат с размером пиксела в 0.15 a.е. по большой полуоси и 0.01 по эксцентриситету. Градации серого цвета основаны на логарифмической шкале, то есть соседние оттенки отличаются друг от друга в 10 раз. Сплошными кривыми отмечены границы зон, внутри которых частицы пересекают орбиту планеты. Позиции 100 тел, указанных первыми в списке транснептунов, отмечены ромбами 


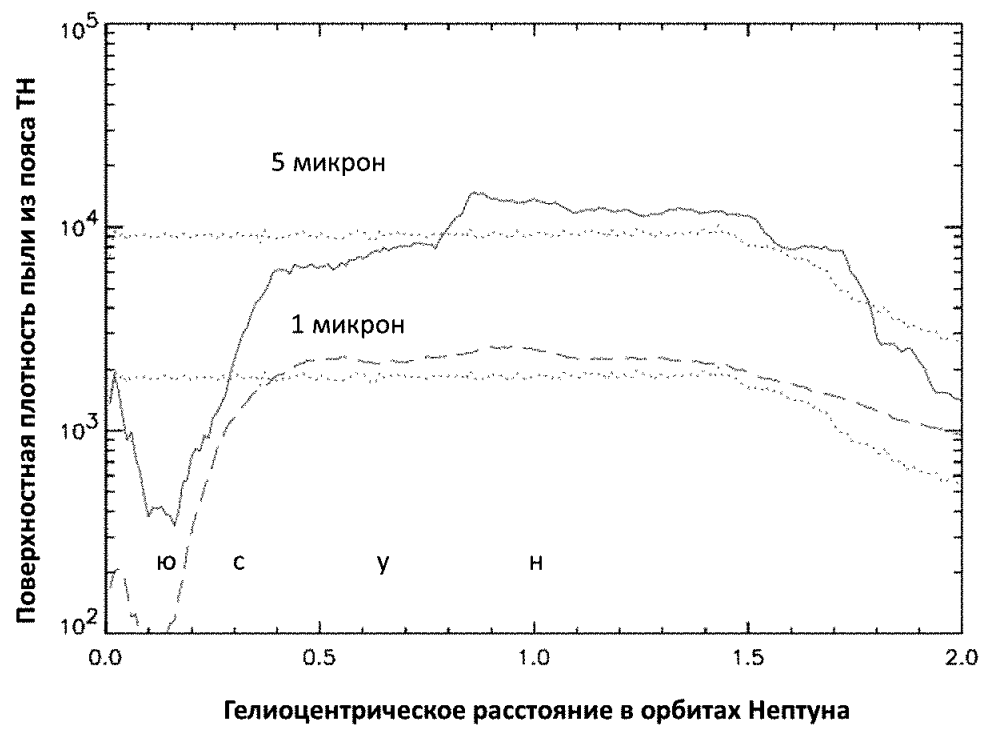

Рис. 3. Поверхностная плотность (в условных единицах, усредненная по интервалу в 0.3 а.е) пыли размером в 1-2 микрона и 5-10 микрон, дрейфующей из пояса транснептунов. Пунктирная линия показывает поверхностное распределение крупных и мелких пылинок в случае отсутствия планет и, соответственно, гравитационного рассеяния

Аналогичные факторы эволюции воздействуют и на частицы, рожденные кометами и астероидами. Последний случай интереснее всего, так как он имеет прямое отношение к уменьшению массы астероидного пояса. Расчеты орбитальной эволюции частиц, унесенных с 110 крупнейших астероидов главного пояса, проводились в работе Горькавого и др. (2000а). Они показывают, что из 110 частиц размером в 1-2 микрона, унесенных в апоцентре орбиты родительских тел, только 85 достигают Земли, остальные 25 частиц попадают в зону Юпитера и покидают Солнечную систему после сильного гравитационного рассеяния. Из 110 микронных частиц, унесенных в перицентре орбиты родительских астероидов, только 57 достигают Земли, остальные 53 частицы выбрасываются Юпитером в межзвездное пространство. Можно оценить, что в среднем около трети микронных частиц, отколовшихся от астероидных тел, за короткое время покидают не только пояс астероидов, но и Солнечную систему.

Эволюция орбит 64 частиц размером в 5-10 микрон показывает, что солнечное давление оказывает на них меньшее воздействие, поэтому эти частицы не достигают зоны Юпитера и дрейфуют внутрь Солнечной системы.

Из приведенных небесномеханических расчетов можно сделать вывод, что на уменьшение массы астероидного пояса работают следующие механизмы:

- частицы разных размеров, дрейфующие из внешних областей Солнечной системы, в подавляющем своем большинстве не попадают в пояс астероидов (см. рис. 1-3);

- каждая частица, взлетевшая над поверхностью астероида из-за удара микрометеорита и попавшая в поле излучения, сразу подвергается эффекту светового давления, который переводит эту частицу на эллиптическую орбиту, а самые мелкие - субмикронные - пылинки переходят на гиперболические орбиты и покидают Солнечную систему.

- микронные частицы астероидного пояса, испытав воздействие солнечного излучения, частично попадают в зону сильных гравитационных возмущений от Юпитера. Около 1/3 таких частиц выбрасывается из Солнечной системы. Этот процесс происходит очень быстро: характерное время 
полета микронной частицы из пояса астероидов к Юпитеру занимает всего несколько лет, а время выброса Юпитером частиц из своей зоны составляет порядка десятков тысяч лет;

- частицы микронных размеров, которые не попадают в зону Юпитера, выметаются эффектом Пойнтинга-Робертсона внутрь Солнечной системы, где падают на Солнце. $100 \%$ крупных и $2 / 3$ мелких астероидных частиц достигают Земли, то есть тоже покидают пояс астероидов благодаря эффекту Пойтинга - Робертсона;

- крупные обломки, не подверженные солнечному влиянию, удаляются из Солнечной системы, если после соударения большие полуоси орбит обломков попадают в зону щелей Кирквуда, где сильно резонансное воздействие Юпитера.

Bсе эти факторы играют значительную роль в уменьшении массы астероидного пояса. Нужно учесть, что все эти механизмы практически перестают действовать с момента образования достаточно крупной планеты, тем самым в зоне Земли и Марса действие этих процессов было сравнительно быстро остановлено, в то время как в поясе астероидов они продолжаются до сих пор.

Для того, чтобы оценить эффективность обсуждаемого механизма, остается исследовать вопрос о том, с какой скоростью образуются пылинки микронных размеров в поясе астероидов.

\section{3 Столкновительное образование пыли}

Каждый удар микрометеорита о поверхность астероида, не говоря уже о столкновении сопоставимых по размеру тел, порождает облако мелкой пыли. Но какова эффективность этого механизма? Какая часть образовавшейся пыли и обломков осядет назад, а какая улетит? Здесь могут оказаться полезными результаты исследования космической японской станцией “Хаябуса” астероида (25143) Итокава, который состоит из хондритов с плотностью 1.9 г/ $\mathrm{cm}^{3}$ и имеет период собственного вращения чуть более 12 часов и размеры $535 \times 294 \times 209$ метров. У астероида нет спутников, но он представляет собой гантелеобразное тело из двух слипшихся объектов. Согласно данным японских исследователей (Нагао и др., 2011), изучивших содержание изотопов инертных газов в образцах поверхностного астероидного реголита, доставленных на Землю, астероид Итокава теряет вещество со своей поверхности со скоростью многих десятков сантиметров за миллион лет. Это привело исследователей к заключению, что время жизни астероида будет составлять 0.1-1 миллиарда лет.

Эти данные являются первым прямым доказательством, что астероиды со значительной скоростью теряют свою массу. Эту потерю нельзя объяснить резонансным влиянием Юпитера, который никак не влияет на поверхностную эрозию астероидов, или взаимодействием с крупными телами зоны Юпитера, которые существовали на протостадии, потому что оценки уменьшения массы астероида Итокава относятся к настоящему времени. Очевидно, что обстрел метеоритами, микрометеоритами и частицами солнечного ветра приводят к тому, что с поверхности Итокавы уносится пыль в большем количестве, чем ее оседает обратно.

Результаты (Нагао и др., 2011) означают, что астероиды километровых размеров, существовавшие на протостадии эволюции астероидного диска, к настоящему времени должны практически исчезнуть. Безусловно, такой значительный эволюционный фактор нуждается в детальном анализе.

Для получения аккуратных численных оценок по уменьшению начальной массы пояса астероидов требуется создание математической модели эволюции астероидной массы, зависящей от переменного распределения по размерам астероидов и частоты соударения тел в поясе астероидов в раннюю эпоху.

\section{4 Заключение}

Существование многочисленных спутников астероидов, которые вырастают на потоке вещества с поверхности родительских тел, и химический анализ образцов с астероида Итокава, который указывает на постоянную убыль поверхностного реголита, позволяют предположить существование эффективного механизма убыли массы астероидного пояса из-за столкновительной эрозии и из-за быстрого 
удаления мелких частиц под воздействием солнечного излучения и гравитационного воздействия планет-гигантов.

Актуальной задачей является создание математических моделей эволюции массы астероидного пояса для оценки эффективности механизма столкновительной эрозии.

\section{Литература}

Витязев А.В., Печерникова Г.В., Сафронов В.С. // Планеты земной группы. Происхождение и ранняя эволюция. М.: Наука. 1990.

Гафтонюк Н.М. и Горькавый Н.Н. // Астрон. вестник. 2013. Т. 47. № 3. С. 196.

Горькавый и др. (Gorkavyi N.N., Ozernoy L.M., Mather J.C. \& Taidakova T.) // NGST Science and Technology Exposition. ASP Series. / Eds Smith E.P. \& Long K.S. 2000a. V. 207. P. 462.

Горькавый и др. (Gorkavyi N.N., Ozernoy L.M., Taidakova T., Mather J.C.) // Distribution of dust from Kuiper Belt Objects. June 29. 2000б. URL: https: / /arxiv.org/pdf/astro-ph/0006435.pdf

Горькавый и Тайдакова (Gorkavyi N. \& Taidakova T.) // Direct Imaging of Exoplanets: Science and Techniques. IAU Colloquium N. 200. / Eds Aime C. and Vakili F. Cambridge Univ. Press. 2006. P. 47. Горькавый Н.Н. // Изв. Крымск. Астрофиз. Обсерв. 2007. Т. 103. № 2. С. 143.

Горькавый Н.Н., Тайдакова Т.А. // Челябинский суперболид. / Ред. Горькавый Н.Н. и Дудоров А.Е. Изд-во Челяб. гос. ун-та. Челябинск. 2016. С. 203.

Диенно и др. (Deienno R., Gomes R.S., Walsh K.J., Morbidelli A., Nesvorny D.) // Icarus. 2016. V. 272. P. 114.

Дхарсандия и др. (Dharsandia P., Pabari J., Patel Ch.) // J. Inform. Knowl. Res. Electron. Comm. Eng. 2017. V. 04. Issue 02. P. 1512.

Минтон и Мальхотра (Minton D.A. and Malhotra R.) // Nature. 2009. V. 457. P. 1109.

Минтон и Мальхотра (Minton D.A. and Malhotra R.) // Icarus. 2010. Issue 2. P. 744.

Нагао и др. (Nagao K., Okazaki R., Nakamura T., et al.) // Science. 2011. V. 333. P. 1128.

Шмидт О.Ю. // Происхождение Земли и планет. М.: Изд. АН СССР. 1962. 